Aleksandra Nikolić

Centralni institut za konzervaciju
УДК 316.774:004.738.5

ДОИ https://doi.org/10.18485/

melissa.2016.15.2.ch21

\title{
MATERIJALNA KULTURA U VIRTUALENDU
}

\section{Sažetak}

Skorašnji razvoj informacionih tehnologija je postavio velike izazove pred pregaoce materijalne kulture iz ugla različitih disciplina i kulturnih praksi i time materijalno učinio latentno aktuelnim pitanjem koje u stopu prati virtuelne kulturne pojave.

Rad se bavi kritičnim osobinama materijalne kulture kao nosioca kulturnog nasleđa i njenom ulogom u transmisiji znanja i vrednosti, te aktuelizuje njen informacijski značaj u svetlu elektronske komunikacije. U radu se takođe razmatraju mogući pristupi transponovanja materijalne kulture u virtuelno okruženje, te eksploatacija informacijskih osobina i vrednosti materijalnog nasleđa u elektronskim medijima. Analizira se uloga, prednosti i ograničenja postojećih virtuelnih formi muzejske prezentacije i vrši se poređenje medioloških osobina fizičkog artefakta sa medijalnošću Interneta, u potrazi za kompatibilnošću i potrebi da se prepozna i razume mogući gubitak vrednosti informacije.

Kroz teorijsko razmatranje paralela između različitih nosilaca kulturne informacije, zasnovanih na dihotomijama materijalno-nematerijalno i fizičko-virtuelno, ispitivanje mogućnosti transponovanja značaja materijalnog nasleđa u virtuelnom okruženju, uzimajući u obzir i domete aktuelnih istraživanja haptičke percepcije u domenu elektronskih medija, vodi ka zaključku da se fizički uslovljena percepcija materijalnog nasleđa postavlja kao preduslov za njegovu elektronsku eksploataciju, ukoliko se teži zaokruženoj kulturnoj informaciji. Ako se ostavi po strani interpretativni deo ovakve eksploatacije, virtuelno generisana informacija i dalje, poput svog materijalnog pandana, služi kao podrška različitim formama učenja čije efekte može značajno da poboljša multisenzorno iskustvo.

Na kraju se uočava paradoksalna promena u pristupu kulturnom nasleđu koju omogućava virtuelno okruženje - dostupnost nasleđa je istovremeno i povećana i umanjena, jer je deo kulturne informacije koju nosi audio-vizuelno dostupnija velikom broju korisnika, ali značajan deo ostaje nedostupan, jer, za sada, može da se generiše samo iz fizičkog prisustva i haptičkog doživljaja predmeta.

Ključne reči: materijalna kultura, kulturno nasleđe, artefakt, digitalizacija, onlajn učenje, virtuelni muzej, muzejske zbirke 


\section{Materijalnost kulture pod lupom}

U poslednjih nekoliko decenija, paralelno sa brojnim i razgranatim istraživanjima osobina i kapaciteta kulturne informacije, kulturno nasleđe je redefinisano na različite načine i u različitim teorijskim i praktičnim formama. Čini se da su presudan uticaj u ovom procesu odigrala istraživanja kritičkog nasleđa, kao posledica postkolonijalne paradigmatske promene (Benet 2004; Smit 2006; Anderman, Arnol-d Simin 2012; Vinter 2013) i daljeg razvoja regulative i sistema zaštite nasleđa. Razvoj sistema zaštite nasleđa može da se prati kroz donošenje ključnih međunarodnih dokumenata, kao što su Bura povelja o konzervaciji mesta od kulturnog značaja australijskog ICOMOS-a (Austalia ICOMOS Charter on the conservation of places of cultural significance 1999 - Burra Charter), UNESCO-va Univerzalna deklaracija o kulturnoj raznovrsnosti (UNESCO Universal Declaration on Cultural Diversity 2001), Okvirna konvencija Saveta Evrope o vrednosti kulturnog nasleđa za društvo (Council of Europe Framework Convention on the Value of Cultural Heritage for Society 2005), Konvencija o zaštiti i unapređenju raznolikosti kulturnih izraza (Convention on the Protection and Promotion of the Diversity of Cultural Expressions 2005).

Iz potrebe da se u definisanju kulturnog nasleđa ode dalje od materijalnosti, te da se fenomen, a time i pojam, proširi na druge kulturne pojave koje nose informacije i prakse vredne međugeneracijske i unutargeneracijske transmisije, pojavilo se shvatanje kulturnog nasleđa kao procesa (Smit 2006). Ovaj koncept odlazi u pravcu definisanja celokupnog nasleđa kao nematerijalnog, gde se artefakti, umetnički predmeti, spomenici, objekti i lokaliteti sele u domen medijuma, sredstva ili nosioca, a ne više nasleđa po sebi (Smit 2006). Istovremeno, pojavom procesualnog i bihejvioralnog shvatanja nasleđa, do izražaja je došlo i razgraničenje materijalnog i fizičkog u nasleđu, imajući u vidu brojne kulturne prakse sa snažnim fizičkim karakterom, koje vrlo jasno spadaju u domen nematerijalnog, poput tradicionalnih igara ili ritualnih pokreta.

\section{Razvoj informacionih tehnologija}

Otkada je Internet "eksplodirao", čini se da je eksplodirala i dostupnost informacija. Ako ne eksplodirala, a ono u najmanju ruku 
počela da se širi kontinualno i u svim pravcima. U želji da se izbegne zamka definisanja kulturne informacije, odnosno njenog izdvajanja iz informacijske poplave u virtuelnom okruženju koje je generisao razvoj Interneta, možda je najbolje usmeriti pažnju na virtuelne pojave koje su najbliže tradicionalnom shvatanju kulturnog nasleđa - virtuelne muzeje.

Istorija onlajn virtuelnih muzeja počinje 90-tih godina XX veka, ali ideja virtuelnog muzeja počinje ranije, sa idejama Andre Malroa oličenim u alegorijskom "muzeju bez zidova" (Malro 1967) ili još ranije, u prvoj polovini XX veka, sa “svetskim mozgom” H.G. Velsa (Vels, Mejni 1938). Termin je danas višeznačno korišćen - može da znači pokretnu ili onlajn verziju tradicionalnog muzeja, ali se često odnosi i na zbirku digitalnog sadržaja, obično umetničkog karaktera. U smislu ovog rada, termin virtuelni muzej označava onlajn verziju postojećeg muzeja i digitalnu verziju fizički postojećih muzejskih zbirki.

Interesantno je da je upravo muzej koji je smešten u najstariju namenski građenu muzejsku zgradu prvi, još 1995, lansirao program virtuelnih izložbi koje su se zasnivale na fotografijama muzejskih zbirki. U pitanju je Muzej istorije nauke koji pripada Univerzitetu u Oksfordu i koji je, zahvaljujući univerzitetskoj ekspertizi i opremi koja mu je bila na raspolaganju, uspeo da pokrene muzejsku vebsajt prezentaciju.

Postoje evidentne prednosti razvoja informacionih tehnologija za delatnost muzeja i kulturno nasleđe uopšte. Jedan deo se odnosi na multimedijalne efekte u prezentaciji, drugi deo na nove forme dokumentovanja i upravljačke alatke, treći deo na onlajn pristup. Direktno ili ne, sve su ovo oblici komuniciranja nasleđa ili muzejskog sadržaja i, u odnosu na tradicionalni muzej i njegove zbirke, poboljšavaju ili šire njihovu dostupnost. Ilustracije radi, najveći postojeći onlajn muzej je Virtualni muzej MWNF (Virtual Museum of Museum With No Frontiers), lansiran 2005. godine. Ovu platformu je pokrenula neprofitna međunarodna organizacija MWNF u kontekstu Barselonskog procesa Evro-Mediteranskog partnerstva u cilju zajedničke transnacionalne prezentacije kulture i umetnosti uključenih zemalja. Zahvaljujući platformi, artefakti, umetnička dela, arheološka nalazišta i spomenici kulture zemalja-članica se prezentuju virtuelno, čime se izbegavaju skupa, dugotrajna i komplikovana putovanja i organizacija 
izložbi, a omogućavaju se virtuelne izložbe na zajedničke teme, koje na neki drugi način ne bi mogle ni da se otvore.

\section{Transmisija nasleđa}

$\mathrm{U}$ ispitivanju osnovne kompatibilnosti kulturnog nasleđa i virtuelnog okruženja, moguće je poći i putem mehanizma prenošenja. Jasno je da onlajn komunikacija donosi potpunu novinu u shvatanju procesa i mehanizama kulturne transmisije, a ona se najjasnije očitava u pojavi memetike, odnosno potpunom redefinisanju ili bar razradi pojma mema, koji vuče svoje pojmovne korene iz teorijske postavke Ričarda Dokinsa (Dokins, 2010). Memi, zamišljeni kao kulturni pandan genima, transponovani u prostor gotovo neograničenih mogućnosti informacijske razmene onlajn okruženja, sve više dobijaju karakteristike virusa. U tom polju slobodne razmene, odašiljanja i preuzimanja ili kopiranja, informacija može da nosi vrednost, ideju ili oblik ponašanja koji imaju kulturne osobine.

$U$ analizi i tumačenju uslova koji se postavljaju pred materijalnu kulturu u virtuelnom okruženju, potrebno je napraviti još jedno razgraničenje - ono između transmisije i komunikacije. Režis Debri (Debri 2004) ovo razgraničenje jasno predstavlja iz ugla mediologije - transmisijom se prenosi značenje, dok se komunikacija odnosi samo na prenošenje informacije. Kulturna transmisija, pored horizontalne, može da bude i vertikalna i kosa, tj. da uključuje i prenošenje informacije kroz vreme putem aktivnih subjekata u međugeneracijskom kontaktu ili, indirektno, putem artefakata koji su nosioci značenja. Vremenska dimenzija komunikacije je drugačijeg karaktera - informacija, odnosno poruka koja je predmet komunikacije je trenutna (Debri 2004, str. 5), odnosno sam komunikacioni proces je kratkotrajan. Otuda je i prvi nivo Internet komunikacije kratkotrajna razmena informacija. Međutim, drugi nivo posmatranja Interneta kao nosioca informacije zadire u fenomen čuvanja, arhiviranja informacija ili, uslovno rečeno, pamćenja (Ernst 2004, Džounz 2007). Strogo uzevši, informacije se zaista pohranjuju na serverima i drugim materijalnim nosiocima koji podržavaju onlajn razmenu u virtuelnom okruženju. Ovde bi mogla da se povuče paralela između artefakata kao materijalnih nosilaca 
kulturne informacije i Interneta, odnosno onlajn servera kao "mesta" koja nose informacije različitog karaktera. Obe ove "arhive" zapravo ne mogu da se shvate kao arhive u klasičnom značenju. Internet je dinamičan sistem u kome se informacija konstantno menja, sklapa, dodaje. Ako posmatramo Internet i kao sredstvo transmisije, imajući u vidu pomenuto mediološko razgraničenje, može se reći da Internet lako generiše nova značenja. Slično tome, artefakt, odnosno materijalna kultura generalno, ne može da se posmatra kao arhiva, jer je podložna interpretaciji, ukoliko je transmisija indirektna, odnosno u odsustvu subjekata transmisije. Internet je mreža efemernih i kratkotrajnih komunikacionih kanala koja nadživljava te iste kanale. Artefakt takođe nadživljava trenutne komunikacione i transmisione kanale, ali ultimativno značenje koje nosi zavisi od tumačenja svake generacije. Internet je "multimedijalan", iako zapravo nije "medijalan", već se oslanja na više vrsta percepcije kao komunikacione kanale. Artefakt je inherentno multimedijalan, jer je transmisija koju podržava multisenzorna. Ideja o artefaktu kao pandanu fenotipu je zapravo ideja o artefaktu kao arhivi, koja ne uzima u obzir sve perceptivne faktore uključene u proces spoznaje i zanemaruje funkciju artefakta kao okidača sećanja (Džounz 2007). Nijedna od ove dve "arhive" nije kompletno multisenzorna i multimedijalna ili transmedijalna. Obe imaju transmisioni kapacitet, jer poseduju osnovne preduslove transmisije - pohranjuju značenja i mogu da se percipiraju. U oba slučaja, interpretativna dinamika predstavlja nadgradnju. S obzirom na perceptivnu nepotpunost oba ova medijuma, čini se da bi multisenzorni doživljaj, a time i pun transmisioni kapacitet, mogao da se pronadje u komplementarnom jedinstvu materijalno-virtualnog sredstva transmisije. Međutim, koje mogućnosti se nude?

\section{Virtuelno-materijalna realnost}

Transponovanje komplementarnog odnosa nematerijalnog i materijalnog nasleđa u virtuelni prostor zahteva uspostavljanje istovrsnog odnosa između virtuelnog i materijalnog. Komplementarnost ovde može da uzme različite forme, ali se svaka odnosi na dopunjavanje multisenzornog doživljaja predmeta kulturnog nasleđa, a time i povećanja mogućnosti ekstrakcije značenja. 
Istraživanja kognitivnih osnova taktilne percepcije (Heler 1992, Šomstin, Jantis 2004, Galas, Spens 2008, Dramond, Šomstin 2010, Galas, Spens 2014, Jildrim 2014, Etsi, Galas 2016) potkrepljuju teorije o važnosti fizičkog kontakta za ljudsko poimanje sveta. Teorija "slepčevog štapa", koja se bavi značajem i značenjem artefakata kao pomagala u čovekovom doživljaju okruženja, zasniva se na stavu da materijalna kultura nije samo proizvod kognitivnih promena, već jedan od mogućih njenih uzroka (Malafuris 2008). Ove teorije istovremeno govore o ograničenjima informativnosti virtuelnog muzeja. Materijalni nosilac značenja je, u tom smislu, informativna dopuna digitalnom podatku, a teško da ovaj odnos može da se obrne jer, da bi artefakt bio iskorišćen kao digitalizovana informacija koja se virtuelno prenosi, ta informacija prvo mora da se prepozna u fizičkom svetu. Ceo postupak izgradnje digitalnog podatka u muzejskim onlajn bazama, odnosno izgradnje muzejske onlajn zbirke, u mnogome zavisi od pripreme koja se dešava u realnom, oflajn životu muzejskih zbirki. Ta priprema podrazumeva istraživanje koje se u značajnoj meri oslanja na fizička ispitivanja. Virtuelni muzeji koji su "ogledalo" postojećih fizičkih muzeja se još uvek u značajnoj meri oslanjaju na materijalne zbirke. Izgled i sadržaj podataka sa meta-podacima u okviru muzejskih baza-podataka dostupnih onlajn donekle zavisi od vrste muzeja, odnosno vodeće namene zbirke. Većina umetničkih i drugih virtuelnih muzeja koja se opredeljuje za kontekstualno tumačenje digitalizovanih artefakata ne stavlja akcenat na meta-podatke, odnosno kontekstualne informacije o samom artefaktu, već ih postavlja u određeni kontekstualni odnos i nudi interpretaciju ili više mogućih interpretacija njegovog porekla i značaja. Za razliku od toga, univerzitetski muzeji i zbirke koji se javljaju na Internetu kao baze podataka uporedive sa bazama podataka univerzitetskih biblioteka, bliži su pružanju meta-podataka koji sadrže direktne rezultate prethodnih istraživanja artefakta. Takvih muzejskih baza podataka² je dovoljno da pojasne i potvrde prednosti i nedostatke virtuelnog prisustva muzealizovanih artefakata kada je reč o istraživačkim i obrazovnim potrebama. muzeja (www.pomui.unimore.it) i MIMO - Konzorcijum evropskih muzeja muzičkih instrumenata (www.mimo-db.eu) koji uključuje i zbirku Univerziteta u Edinburgu, a koji je dostupan i preko Europeana portala (www.europeana.eu). 
Čak i kada ovakvih potreba onlajn ne bi bilo, multisenzorni doživljaj koji, za sada, nudi virtuelno okruženje, ne upotpunjuje ni estetski doživljaj artefakta, jer haptički doživljaj materijalnosti predstavlja značajan deo tog doživljaja.

\section{Virtuelni artefakt kao obrazovno sredstvo}

Ako ostavimo estetski aspekat po strani i vratimo se obrazovnoj funkciji materijalne kulture, u fizičkom ili virtuelnom svetu, ona se javlja kao sredstvo učenja. Obrazovni pristup koji se oslanja na materijalnu kulturu u fizičkom svetu poznat je pod nazivom object-based learning, odnosno učenje putem predmeta. Eksploatisan je na univerzitetima, prvenstveno u okviru akademskih programa kojima je materijalna kultura od interesa (Čaterdži 2011, Daz 2011, Ladkin 2011, Meri 2011). S obzirom da se najčešće koristi tamo gde postoje univerzitetske zbirke ili muzejske zbirke na raspolaganju akademskoj zajednici, često se javlja i kao podrška programima u vezi sa istorijom nauke i tehnologije. Interes za korišćenje artefakata u nastavi postoji čak i kada je u pitanju materijalnost kao sekundarna osobina ili informacija koju poseduju pisani izvori - stara i retka knjiga ili arhivski materijal, koji je od posebnog značaja za studente istorije ili bibliotekarstva. Imajući u vidu preimućstva učenja putem predmeta i fokus na taktilnom, odnosno haptičkom doživljaju materijalne kulture, postavlja se pitanje mogućnosti transponovanja vrednosti ovog modaliteta u virtuelnu realnost, odnosno pronalaženje odgovarajućeg virtuelnog pandana.

Ako svedemo značaj $O B L$ pristupa na fizički kontakt sa materijalom i prikupljanje informacija kao jedinstvenu kombinaciju obrazovnog sredstva i obrazovnog efekta, onda se automatski problem transponovanja modaliteta u virtuelnu sredinu svodi na fizikalnost, kao njegovu suštinu. Zašto fizički kontakt može da se shvati kao obrazovno sredstvo? Pored ranije pomenutih kognitivnih, odnosno perceptivnih aspekata, postoji čitav dijapazon tehnika ispitivanja materijala koje pružaju značajnu podršku nauci i obrazovanju, a utemeljene su na fizičkom kontaktu, čak i kad on nije direktan. lako su makroskopska ispitivanja materijala i površina ar- 
tefakata putem digitalnih slika sve više moguća, analitičke tehnike na samom materijalu i dalje predstavljaju nezamenjiv izvor informacija o poreklu i vrednostima materijalne kulture. Ovako prikupljene informacije postaju metapodatak u digitalizovanoj formi i osnova za onlajn edukaciju.

\section{Totalitet kulture i paradoks onlajn pristupa}

Dostupnost može da se posmatra u različitim ravnima. Pitanje dostupnosti je izuzetno eksploatisano u vezi sa temom autorskih prava, ali se, istovremeno, nezanemarljiv broj istraživačkih poduhvata fokusirao na temu digitalne i onlajn dostupnosti kulturnih dobara (Kameron 2003; Kameron, Robinson 2007; Vang, Arojo, Staš, Rutlidž 2007; Van Nulan, Van Erp, Arojo 2012).

Međutim, iako se postavljanjem kulturne informacije na mrežu širi njena dostupnost, neminovna je devalvacija do koje dolazi digitalizacijom i oduzimanjem materijalnog aspekta iz njenog totaliteta. Ovime se dolazi do paradoksa dostupnosti kulture u virtuelnoj realnosti - ona u svojoj virtuelnoj verziji postaje istovremeno i dostupnija i manje dostupna, s obzirom da informacija stiže do većeg broja ljudi, ali bez svog materijalnog nosioca, u kome se svakako nalazi deo informacije. Ovde je zgodno vratiti se na pregalaštvo organizacije Museum with no Frontiers. Čini se kao da projekat Virtuelnog muzeja MWNF čini upravo ono što je, za sada, najviše moguće u svrhu obezbeđivanja pristupa muzejskim zbirkama jednog regiona - one su digitalizovane, postavljene na onlajn platformu u formi otvorenog repozitorijuma sa relevantnim pratećim podacima, ali su i tematski unakrsno povezane prema različitim kulturnim, istorijskim, društvenim i umetničkim kriterijumima u izložbene celine, dakle smeštene u druge kontekste putem različitih interpretacija. One ostaju fizički dostupne za jedan deo potencijalne publike, ali se istovremeno nude široj masi korisnika kroz druge forme i koncepte. Maksimalan multimedijalni muzejski sadržaj u postojećim tehnološkim i ekonomskim okvirima.

Konsenzus oko jedinice kulture, odnosno osobina kulturne informacije, i dalje ne postoji i ostaje pitanje koliki deo informacije se vezuje za njena materijalna i nematerijalna svojstva. $S$ druge strane, rezultati pomenutih istraživanja i navedena stručna praksa govore u prilog humanističkoj 
i, specifično, kulturološkoj, studijskog i obrazovnoj potrebi za fizičkim kontaktom, kada je u pitanju čovekovo materijalno okruženje. Imajući u vidu ovaj deo multisensornog iskustva, virtuelna platforma poput Interneta još uvek ne može da sakupi sve znanje, jer značajan deo esencije kulture postoji samo u materijalnoj formi. $U$ budućnosti može da se zamisli transmisija kulture koja se ne odvija ni vertikalno ni horizontalno ni koso, već radijalno, iz jednog centra poput današnjeg Interneta, ali do konkretnijih predviđanja u ovom pravcu će moći da se dođe tek kada se prepoznaju istinski dometi transponovanja materijalnog u virtuelno okruženje, za sada bar delimično oličenog u haptičkim istraživanjima.

\section{Literatura}

Anderman, Arnol-d Simin 2012: Andermann, J. and Arnold-de Simine, S. Introduction Memory, Community and the New Museum. Theory, Culture \& Society, 29(1), pp.3-13.

Benet 2004: Bennett, T. Pasts beyond memory: Evolution, museums, colonialism. Psychology Press.

Ernst 2004: Ernst, W. The archive as metaphor. No) Memory: Storing and Recalling in Contemporary Art and Culture. Rotterdam: NAi.

Džounz 2007: Jones, A. Memory and material culture. Cambridge: Cambridge University Press. Kin 2006: Keene, S. Fragments of the world: uses of museum collections. Routledge.

Smit 2006: Smith, L. Uses of heritage. Routledge.

Vinter 2013: Winter, T. Clarifying the critical in critical heritage studies. International Journal of Heritage Studies, 19(6), pp.532-545.

Burra Charter (Austalia ICOMOS Charter on the conservation of places of cultural significance) - 1999 - Australia ICOMOS

UNESCO Universal Declaration on Cultural Diversity - 2001 - General Conference of UNESCO

Convention on the Protection and Promotion of the Diversity of cultural Expressions / Paris 2005

Council of Europe (2005) Framework Convention on the Value of Cultural Heritage for Society, European Treaty Series 199, [http://conventions.coe.int/Treaty/EN/ Treaties/Html/199.htm]

Debri 2004: Debray, R., \& Rauth, E. Transmitting culture. Columbia University Press.

Dokins 2010: Dokins, R. Sebični gen. Heliks, str. 209-211.

Jildrim 2014: Yildirim, I. From perception to conception: learning multisensory representations.

Šomstin, Jantis 2004: Shomstein, S. and Yantis, S. Configural and contextual prioritization in object-based attention. Psychonomic bulletin \& review, 11(2), pp.247-253. 
Galas, Spens 2014: Gallace, A. and Spence, C. In touch with the future: The sense of touch from cognitive neuroscience to virtual reality. OUP Oxford.

Heler 1992: Heller, M.A. Haptic dominance in form perception: vision versus proprioception. Perception, 21(5), pp.655-660.

Etsi, Galas 2016: Etzi, R. and Gallace, A. The arousing power of everyday materials: an analysis of the physiological and behavioral responses to visually and tactually presented textures. Experimental brain research, 234(6), pp.1659-1666.

Galas, Spens 2008: Gallace, A. and Spence, C. The cognitive and neural correlates of "tactile consciousness": A multisensory perspective. Consciousness and cognition, 17(1), pp.370-407.

Dramond, Šomstin 2010: Drummond, L. and Shomstein, S. Object-based attention: Shifting or uncertainty?. Attention, Perception, \& Psychophysics, 72(7), pp.1743-1755.

Malafuris 2008: Malafouris, L. Beads for a plastic mind: The 'Blind Man's Stick'(BMS) hypothesis and the active nature of material culture. Cambridge Archaeological Journal, 18(03), pp.401-414.

Čaterdži 2011: Chatterjee, H.J. Object-based learning in higher education: The pedagogical power of museums. International Committee for University Museums and Collections (UMAC) Proceedings, 3.

Ladkin et al. 2011: Ladkin, N., Johnson, E., Baker, R.J. and Chatterjee, S. The use of collections in research and teaching at the Museum of Texas Tech University. International Committee for University Museums and Collections (UMAC) Proceedings, 3.

Daz 2011: Duhs, R. Learning from university museums and collections in higher education: University College London (UCL). International Committee for University Museums and Collections (UMAC) Proceedings, 3.

Meri 2011: Marie, J. The role of object-based learning in transferable skills development. International Committee for University Museums and Collections (UMAC) Proceedings, 3.

Vang et al. 2007: Wang, Y., Aroyo, L.M., Stash, N. and Rutledge, L. Interactive user modeling for personalized access to museum collections: The rijksmuseum case study. In International Conference on User Modeling (pp. 385-389). Springer Berlin Heidelberg.

Van Nulan et al. 2012: van Nuland, A., van Erp, M. and Aroyo, L. Towards Cultural Heritage Communities Online.

Kameron, Robinson 2007: Cameron, F. and Robinson, H. Digital knowledgescapes: Cultural, theoretical, practical, and usage issues facing museum collection databases in a digital epoch. Theorizing digital cultural heritage: A critical discourse, p.165.

Kameron 2003: Cameron, F. Digital Futures I: Museum collections, digital technologies, and the cultural construction of knowledge. Curator: The Museum Journal, 46(3), pp.325-340.

Vels 1938: Wells, H.G. and Mayne, A.J. World brain. Methuen \& Company.

Malro 1967: Malraux, A. Museum without walls. 